\title{
Histological Regression of Squamous Esophageal Carcinoma Assessed by Percentage of Residual Viable Cells after Neoadjuvant Chemoradiation is an Important Prognostic Factor
}

\author{
Daniel King Hung Tong, MBBS, MS, FRACS, FCSHK, FHKAM ${ }^{1}$, Simon Law, MS, MA (Cantab), MBBChir., \\ FRCSEd, FCSHK, FHKAM, FACS ${ }^{1}$, Dora Lai Wan Kwong, MBBS, MD, FRCR, FHKCR, FHKAM ${ }^{4}$, \\ Kwok Wah Chan, MBBS, FRCPPath, FHKCPath, FHKAM ${ }^{2}$, Alfred King Yin Lam, MBBS, PhD, MD, FRCPA, \\ FRCPath $^{3}$, and Kam Ho Wong, MBBS, FRCSEd, FCSHK, FHKAM ${ }^{1}$
}

${ }^{1}$ Department of Surgery, The University of Hong Kong, Queen Mary Hospital, Hong Kong, China; ${ }^{2}$ Department of Pathology, The University of Hong Kong, Queen Mary Hospital, Hong Kong, China; ${ }^{3}$ Department of Pathology, Griffith Medical School, Griffith University, Gold Coast, Australia; ${ }^{4}$ Department of Clinical Oncology, The University of Hong Kong, Queen Mary Hospital, Hong Kong, China

\begin{abstract}
Background. Whether the TNM staging system is applicable after neoadjuvant chemoradiation in esophageal cancer is controversial. The aim of this study was to evaluate the prognostic value of histopathological regression of the primary tumor in postchemoradiated patients.

Materials and Methods. The pretherapeutic and pathological ypTNM stages of patients who have had neoadjuvant chemoradiation followed by esophagectomy were analyzed. The percentage of residual viable cells of the primary tumor (ypV) and other clinicopathological factors were tested for their prognostic value.

Results. Of 175 recruited patients, 55 (31.4\%) achieved pathological complete response. The median survival of these 55 patients was significantly longer than those with other disease stages $(124.8$ vs 21.1 months $)(P<.001)$. Gender, ypT, ypN, ypTNM, and ypV stage were significant prognostic factors in univariate analysis. In patients without nodal metastases, the median survival in patients with residual viable cells in the primary tumor $(\mathrm{ypV}+)$ was 24.6 months, compared with that of 124.8 months in those with no viable cells $(y p V 0)(P=.043)$. In those who had
\end{abstract}

(C) The Author(s) 2010. This article is published with open access at Springerlink.com

First Received: 29 November 2009;

Published Online: 9 March 2010

S. Law, MS, MA (Cantab), MBBChir., FRCSEd, FCSHK, FHKAM, FACS

e-mail: slaw@hku.hk nodal metastases, the median survival of patients with ypV0 and $\mathrm{ypV}+$ were 21.2 months and 17.4 months respectively $(P=.37)$. Cox regression analysis showed that male gender, high percentage of residual viable cells $(\mathrm{ypV})$, and positive nodal status (ypN1) were independent predictors of poor prognosis.

Conclusions. In patients who underwent neoadjuvant chemoradiation therapy, histopathological regression of the primary tumor indicated by percentage of residual viable cells is an important prognostic factor in addition to nodal status and gender.

The American Joint Committee on Cancer (TNM) staging system is used to stratify esophageal cancer patients for different therapeutic strategies. ${ }^{1}$ The staging system accurately predicts long-term survival in patients treated with surgical resection alone. ${ }^{2}$ For locoregionally advanced esophageal cancer however, the outcome is generally poor after surgical resection. ${ }^{3,4}$ In order to improve outcome, neoadjuvant chemoradiation therapy followed by surgery is increasingly used to treat esophageal cancer. ${ }^{5,6}$ In this situation, it remains unclear if the same TNM staging system is applicable after surgery to guide prognosis. In a previous study, we have demonstrated that ypTNM staging after neoadjuvant chemoradiation was suboptimal in prognostication. ${ }^{7,8}$ Similar findings have also been reported in the literature. ${ }^{7,9,10}$ Evaluating histopathological regression in the surgical specimen may be a better way to assess prognosis. ${ }^{11-13}$ 
The aims of the present study were to investigate the prognostic value of the ypTNM staging system and assess the significance of the percentage of viable residual cells in the esophagus by histopathological examination in patients who had had received neoadjuvant chemoradiation therapy.

\section{PATIENTS AND METHODS}

From 1995 to 2007, 183 patients who had squamous cell esophageal carcinoma and who received neoadjuvant chemoradiation followed by surgery at the Queen Mary Hospital, The University of Hong Kong, were included in this study. Neoadjuvant chemoradiation treatment was given as part of a randomized controlled trial comparing neoadjuvant chemoradiation versus surgical resection alone or when locally advanced tumor or nonregional metastatic nodal spread was present. In these situations, a R0 resection was judged not probable and thus chemoradiation was used upfront. Patients with systemic organ metastases were not selected for surgical treatment and thus were excluded. Only patients who had R0 resections were included in this study because patients who had incomplete tumor resection invariably would have a poor prognosis. Tumors located at the cardia or nonsquamous cell cancers were excluded.

For all patients, staging investigations included upper endoscopy, endoscopic ultrasound (EUS) and bronchoscopy, ultrasound of the neck with or without fine-needle aspiration cytology of suspected nodes, computer tomography (CT), or positron emission tomography fusion with computer tomography (PET/CT) imaging (PET/CT scan was available since 2003). Chemoradiation therapy was given in a concurrent manner. The chemotherapy regime comprised cisplatin at $100 \mathrm{mg} / \mathrm{m}^{2}$ on day 1 and then day 22 and continuous infusion of 5-fluorouracil (5-FU) at $500 \mathrm{mg} / \mathrm{m}^{2}$ per day for 5 days from days 1 to 5 and days 22 to 26. Radiotherapy was given at a dosage of 40-46 Gy at 2 Gy per fraction. It was delivered through anterior and posterior opposing fields to the primary esophageal tumor covering at least $1-\mathrm{cm}$ lateral margins and $3-\mathrm{cm}$ axial margins. Postchemoradiation evaluation was performed 4 weeks after the date of finishing the treatment course, and surgery carried out soon after.

The choice of surgical approach was governed by the location of the tumor. For tumors located in the middle and lower thirds of the esophagus a Lewis-Tanner esophagectomy through an abdominal-right thoracotomy approach was preferred, but three-phase esophagectomy and minimally invasive techniques using thoracoscopic \pm laparoscopic approaches have been increasingly employed in recent years. Two-field lymph node dissection was performed. Bilateral cervical nodal dissection was not routine because evidence was not strong enough to demonstrate clear benefits over two-field lymphadenectomy but with potentially increased morbidities. ${ }^{14,15}$

\section{Pathological Analysis}

Pathological preparation of the surgical specimen started immediately after the operation. A surgeon identified the lymph node groups in the specimen. They were dissected and labeled separately from the main esophageal specimen. Two designated pathologists (KWC, AKYL) were responsible for the histological examination. The esophagus was fixed in $10 \%$ neutral formalin overnight, serially sectioned, and embedded into paraffin blocks. Sections were cut at $5 \mu \mathrm{m}$ thickness and stained with hematoxylin and eosin for microscopic examination. The tumor zone on the slide was labeled respectively as scar tissue, necrotic tissue, and viable tumor. Percentage of the viable residual tumor was then calculated by dividing the viable residual tumor area by the total tumor area, which is the sum of the areas categorized under the tumor zone. The percentage of viable residual tumor was designated as a continuous variable and also categorized into 4 groups as a measure of the extent of chemoradiation response: ypV0, no viable cell; ypV1, 1\%-33\% viable tumor; ypV2, 34\%-66\% viable tumor; and $\mathrm{ypV} 3,67 \%-100 \%$ viable tumor, according to the Guidelines of Japanese Society for Esophageal Disease. ${ }^{16}$ The deepest layer involved by malignant cells determined the ypT-stage. The total number of harvested lymph nodes and the location and the number of lymph nodes with metastasis were recorded. A final pathologic stage (ypTNM stage) was then assigned to each specimen according to the American Joint Committee on Cancer criteria.

\section{Statistical Analysis}

All data were collected prospectively. Categorical data were analyzed using chi-square and Fisher exact tests where appropriate. Continuous variables are expressed as median (range). Survival was calculated by the KaplanMeier method from the date of operation to the time of death or last date of assessment. Log-rank test was used to compare survival difference between groups. Prognostic factors for survival were assessed using Cox regression for univariate analysis and Cox proportional hazards models were fitted for multivariate analysis (backward stepwise [conditional LR]). Differences between groups were considered statistically significant if the $P$ values were less than .05. The statistical analysis was performed with SPSS Software for Windows (SPSS, Chicago, IL). 
TABLE 1 Demographic features of patients treated with neoadjuvant chemoradiation and univariate analysis of survival in relation to clinicopathological characteristics

\begin{tabular}{|c|c|c|c|c|}
\hline Characteristics & No. of patients $(n=175)(\%)$ & HR & $(95 \% \mathrm{CI})$ & $P$ value \\
\hline Age, median (range) & $65(38-82)$ & 0.994 & $0.974-1.015$ & .596 \\
\hline Gender & & & & .004 \\
\hline Male & $149(85.1)$ & 3.1 & $1.422-6.761$ & \\
\hline Female (reference) & $26(14.9)$ & 1 & & \\
\hline Level of tumor & & & & .787 \\
\hline Cervical (reference) & $2(1)$ & 1 & & \\
\hline Upper & $32(18.3)$ & 1.330 & $0.175-10.101$ & .783 \\
\hline Middle & $104(59.5)$ & 1.838 & $0.254-13.321$ & .547 \\
\hline Lower & $31(17.7)$ & 1.762 & $0.233-13.319$ & .583 \\
\hline Double & $6(3.5)$ & 1.253 & $0.113-13.902$ & .854 \\
\hline \multicolumn{5}{|l|}{ Clinical stage (pretreatment) } \\
\hline cT stage & & & & .300 \\
\hline $\mathrm{cT} 1$ & $3(1.7)$ & 1 & & \\
\hline $\mathrm{cT} 2$ & $14(8.0)$ & 1.556 & $0.285-8.503$ & .610 \\
\hline cT3 & $149(85.1)$ & 0.500 & $0.133-1.876$ & .304 \\
\hline cT4 & $9(5.1)$ & 1.174 & $0.429-3.215$ & .755 \\
\hline $\mathrm{cN}$ stage & & & & .246 \\
\hline $\mathrm{cNO}$ & $37(21.1)$ & 1 & & \\
\hline $\mathrm{cN} 1$ & $138(78.9)$ & 1.352 & $0.812-2.252$ & \\
\hline cM stage & & & & .194 \\
\hline $\mathrm{cM} 0$ & $146(83.4)$ & 1 & & \\
\hline cM1 & $29(16.6)$ & 1.432 & $0.833-2.460$ & \\
\hline cTNM stage & & & & .281 \\
\hline c-stage I (reference) & $3(1.7)$ & 1 & & \\
\hline c-stage II & $33(18.8)$ & 0.487 & $0.111-2.133$ & .340 \\
\hline c-stage III & $110(62.9)$ & 0.727 & $0.177-2.983$ & .658 \\
\hline c-stage IV & $29(16.6)$ & 0.951 & $0.218-4.145$ & .947 \\
\hline \multicolumn{5}{|l|}{ Pathological stage } \\
\hline ypT stage & & & & .006 \\
\hline ypT0/pTis (reference) & $78(44.6)$ & 1 & & \\
\hline ypT1 & $17(9.6)$ & 1.844 & $0.947-3.588$ & .072 \\
\hline урT2 & $36(20.6)$ & 1.485 & $0.841-2.624$ & .173 \\
\hline урT3 & $39(22.3)$ & 2.626 & $1.543-4.467$ & $<.001$ \\
\hline ypT4 & $5(2.9)$ & 2.963 & $0.899-9.768$ & .074 \\
\hline ypN stage & & & & .001 \\
\hline ypN0 (reference) & $111(63.4)$ & 1 & & \\
\hline ypN1 & $64(36.6)$ & 2.020 & $1.325-3.081$ & \\
\hline ypM stage & & & & .79 \\
\hline урМ0 (reference) & $161(92)$ & 1 & & \\
\hline ypM1 & $14(8)^{\mathrm{a}}$ & 1.119 & $0.488-2.566$ & \\
\hline ypTNM & & & & .003 \\
\hline ypCR (reference) & $55(31.4)$ & 1 & & \\
\hline ypT0N1M0 & $20(11.4)$ & 2.594 & $1.245-5.406$ & .011 \\
\hline$y$-stage I & $13(7.4)$ & 2.579 & $1.188-5.601$ & .017 \\
\hline y-stage II & $51(29.2)$ & 2.377 & $1.312-4.304$ & .004 \\
\hline y-stage III & $22(12.6)$ & 4.041 & $2.075-7.873$ & $<.001$ \\
\hline$y$-stage IV & $14(8)^{\mathrm{a}}$ & 2.254 & $0.892-5.695$ & .086 \\
\hline
\end{tabular}


TABLE 1 continued

\begin{tabular}{|c|c|c|c|c|}
\hline Characteristics & No. of patients $(n=175)(\%)$ & HR & $(95 \% \mathrm{CI})$ & $P$ value \\
\hline \multicolumn{5}{|l|}{ Residual tumor } \\
\hline ypV stage ${ }^{b}$ & $175(100 \%)$ & 1.334 & $1.127-1.579$ & .001 \\
\hline ypV stage ${ }^{c}$ & & & & .003 \\
\hline ypV0 $(0 \%)$ (reference) & $78(44.6)$ & 1 & & \\
\hline ypV1 (1-33\%) & $42(24)$ & 1.538 & $0.900-2.630$ & .116 \\
\hline ypV2 (34-66\%) & $18(10.3)$ & 2.065 & $1.013-4.209$ & .046 \\
\hline ypV3 (66-100\%) & 37 (21.1) & 2.659 & $1.579-4.476$ & $<.001$ \\
\hline
\end{tabular}

$H R$ hazard ration, $C I$ confidence interval

Reference against which hazard rations are calculated

a Stage IV by virtue of distant nodal metastases, distant organ metastases patients were excluded

${ }^{\mathrm{b}} \mathrm{pV}$ stage tested as a continuous variable

${ }^{\mathrm{c}} \mathrm{pV}$ stage tested as a categorical variable

\section{RESULTS}

Of the 183 patients who had chemoradiation followed by surgery, 175 had total tumor clearance (R0) achieved and were included in this study. Among these patients, 149 were men and the median age was 65 (range, 38-82). The median follow-up was 20 months (range, 1-143). The demographic data of these patients are shown in Table 1 .

\section{Effects, Morbidities, and Mortalities}

A total of $132(75.4 \%)$ patients had their tumor downstaged, the tumor status of 35 patients $(20.0 \%)$ remained unchanged, and 8 patients (4.6\%) had disease progression after chemoradiation. For surgery-related morbidities, 9 patients $(5.1 \%)$ had anastomotic leakage and 5 patients (2.9\%) had chylothorax. Major medical complications including chest infection, arrhythmia, and myocardial infarction occurred in 20 patients (11.4\%). Also, 1 patient $(0.6 \%)$ died in hospital. He had a prolonged stay in hospital after surgery because of socioeconomic reason. He eventually died of pneumonia with no evidence of recurrence.

\section{Survival Analysis}

At the time of data analysis, 73 patients had died; 17 of them died from non-tumor-related cause. Overall survival was investigated. The overall median survival of all patients was 39.2 months. The 3-year and 5-year survival rates were $52.8 \%$ and $40.2 \%$, respectively. Univariate analysis showed that the pretreatment clinical stage was not a predictor of overall survival. The potential prognostic factors identified were gender, pathological $\mathrm{T}$ stage (ypT), pathological $\mathrm{N}$ stage (ypN), and the overall pathological stage (ypTNM) (Table 1). ypV stage was tested as both a continuous and categorical variable. For the latter, the ypV stage was categorized into 4 groups according to the Guidelines of Japanese Society for Esophageal Disease. In either situation, ypV stage was a significant prognostic factor in univariate analysis.

Male gender was a predictor of poor survival, and the survival curve is shown in Fig. 1a. Overall, ypTNM stagespecific survival curves are shown in Fig. 1b. No statistical difference could be identified between each stage of disease by log-rank test. The median survival of the 55 patients $(31.4 \%)$ who had pathological complete response (ypT0NOM0) was significantly longer compared with those with other ypTNM stages combined, at 124.8 months vs 21.1 months, $P<.00$ (Fig. 1c).

Survival curves of different ypT stages from analysis of the primary tumor status are illustrated in Fig. 2a. Advancing ypT stages had worse prognosis. The median number of harvested lymph nodes was 22 (range, 0-97). Among the study group, 64 patients $(36.6 \%)$ had positive malignant lymph nodes $(\mathrm{ypN}+)$. The median survival of patients with nodal metastases was 21 months compared with 65.2 months in patients without nodal metastases $(P<.001)$ (Fig. 2b). Of the 111 patients (63.4\%) without nodal metastasis, 56 (32\%) had viable malignant cells identified in the primary tumor $(\mathrm{ypV}+)$. The median survival of these patients was 24.6 months, which was significantly worse when compared with the 55 patients $(31.4 \%)$ who had no viable cells in the primary tumor (ypV0), whose median survival was 124.8 months $(P=.043)$ (Fig. 2c). In contrast, in patients who had nodal metastases, survival of patients with ypV0 and $\mathrm{ypV}+$ was not significantly different; median survival was 21.2 months and 17.4 months, respectively $(P=.368)$ (Fig. 2d).

Multivariate analyses using Cox proportional hazard model for survival is shown in Table 2. $\mathrm{ypV}$ as a continuous variable, gender, ypT, ypN and overall ypTNM stage were entered into the model. Male gender, the percent of 
a

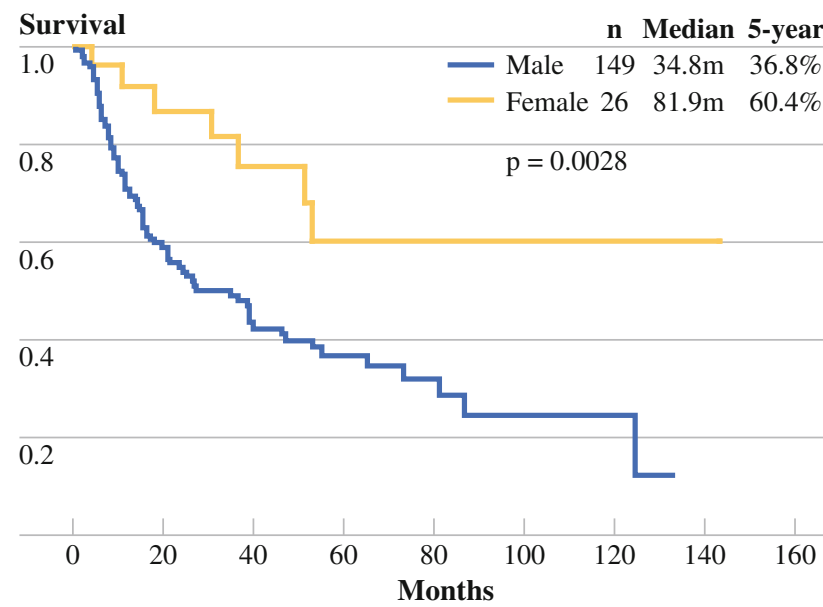

b

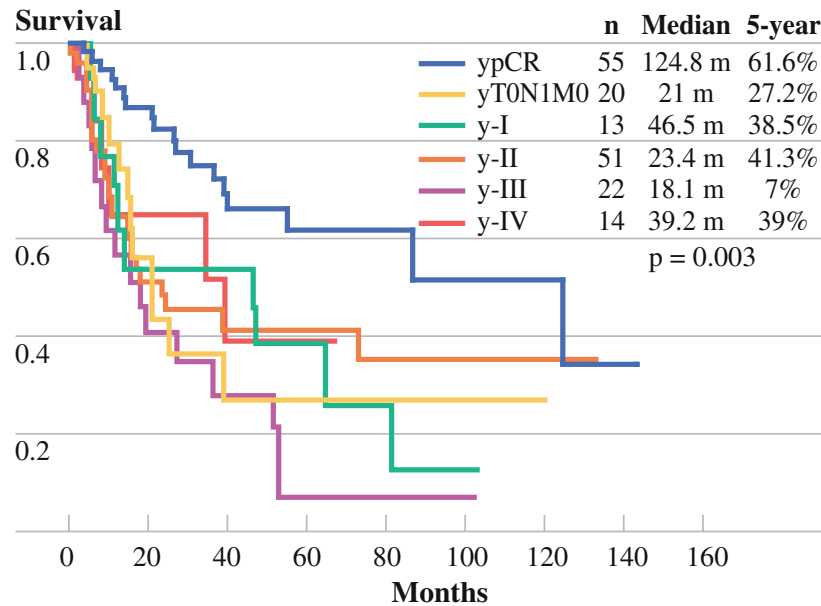

c

Survival n Median 5-year

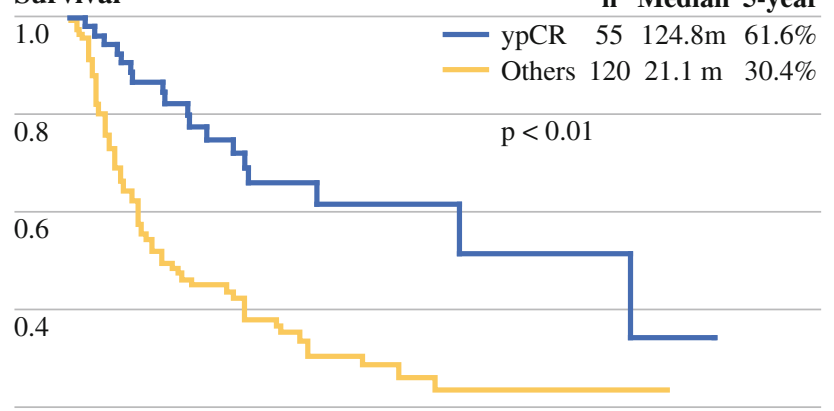

0.2

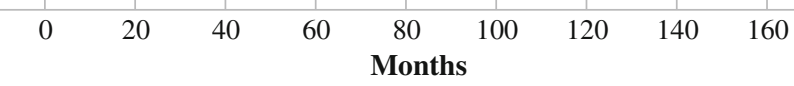

FIG. 1 a Survival curve with gender as a predictor of survival. b Survival curve of overall ypTNM stage for patients treated with neoadjuvant chemoradiation followed by surgery. c Survival curve for patients with pathological complete response (ypCR) and other stages (others) of disease viable malignant cells in the primary tumor $(\mathrm{ypV})$, and presence of metastatic lymph node (ypN) were independent predictors of poor prognosis. Survival of subcategories of $\mathrm{ypV}$ stages is shown in Fig. 2e. A trend of separation of survival is seen among different $\mathrm{ypV}$ stages. $\mathrm{ypV}$ as a categorical variable, gender, and ypN were re-entered to the Cox model for analysis. All three variables were found to be independent poor prognostic predictors (Table 3).

\section{DISCUSSION}

In this study, we have shown that in patients who underwent neoadjuvant chemoradiation therapy before surgical resection, percentage of viable cells in the primary tumor, nodal status, and gender were prognostic factors on multivariate analysis. ypV stage could potentially replace ypT stage. Nodal status is however even more important; positive nodal metastasis incurs a poor prognosis even in the presence of complete response in the primary tumor.

The beneficial effects of neoadjuvant chemoradiation therapy, although gaining popularity, have not been consistently shown in randomized trials. ${ }^{3,4,17-21}$ However, patients who have pathological complete response (ypTONOM0) after neoadjuvant chemoradiation therapy have repeatedly been shown to have better survival compared with those with incomplete response. ${ }^{22-25}$ In our group of patients, chemoradiation had substantial effects; $75.4 \%$ of patients were downstaged, and $31.4 \%$ achieved complete response. Consistent with other reports, the longterm survival of the complete responders was significantly longer than those patients with residual tumor. ${ }^{4,19,26}$ The 3year and 5-year survival rates in ypCR patients were $72.1 \%$ and $61.6 \%$, respectively.

Pretherapeutic clinical TNM stage had no impact on survival. This is not unexpected since long-term prognosis would depend on the response to neoadjuvant treatment. This is also consistent with the findings from other similar studies. ${ }^{8,27}$ It is however controversial whether postsurgical ypTNM stage is of prognostic significance or not. The relevance of ypTNM has been variably reported by different investigators. ${ }^{10}$ Swisher and associates identified ypTNM as an independent prognostic factor on multivariate analysis, while data from the Memorial Sloan Kettering Center did not find it of value. ${ }^{9}$ Our data could not demonstrate the significance of ypTNM stage on multivariate analysis. ypT stage was not prognostic on multivariate analysis, only ypN was useful. The reason that ypTNM stage was not prognostic may be related to an altered relationship between ypT and ypN stage. In our previous study, we have shown that while in patients who had sur- 
FIG. 2 a Survival curve dependent on ypT stage disease. $\mathbf{b}$ Survival curve for patients with $(\mathrm{ypN}+)$ or without (ypN0) nodal metastases. c Survival curve of ypV0 (without residual malignant cells in primary tumor) versus $\mathrm{ypV}+$ (with residual malignant cells) in patients with ypNO. d Survival curve of ypV0 (without residual malignant cell in primary tumor) versus $\mathrm{ypV}+$ (with residual malignant cell) in patients with ypN+. e Survival curve of patient in relation to the amount of viable cell categorized according to the Guidelines of Japanese Society for Esophageal Disease

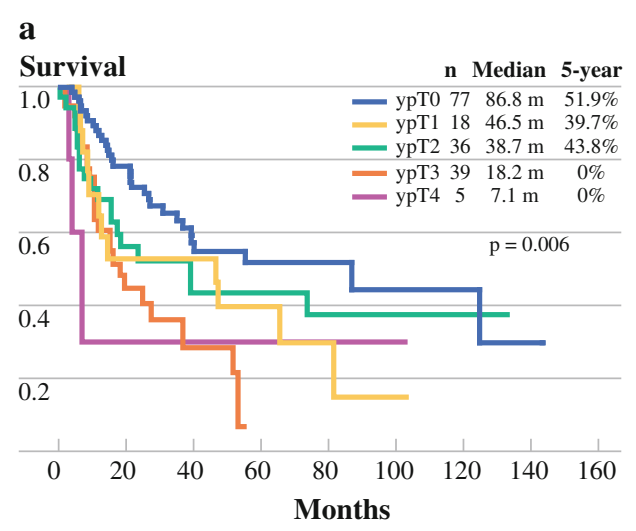

$$
\text { c }
$$
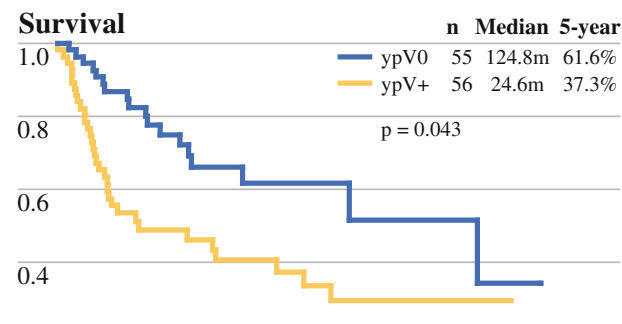

$\overline{0.2}$

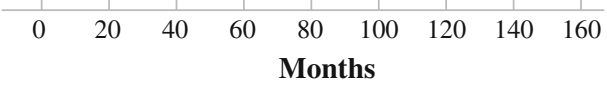

e

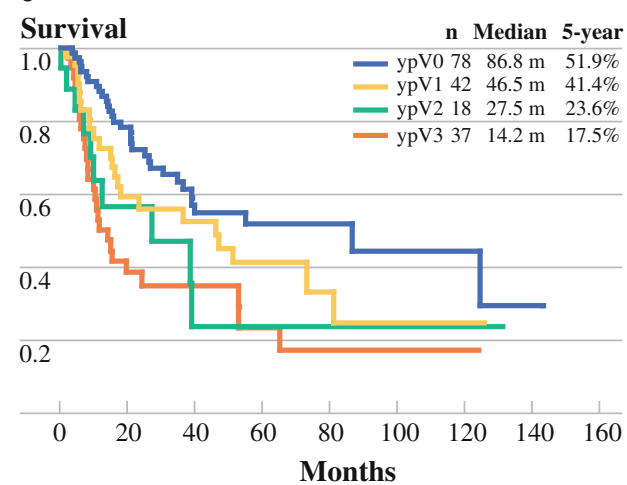

b

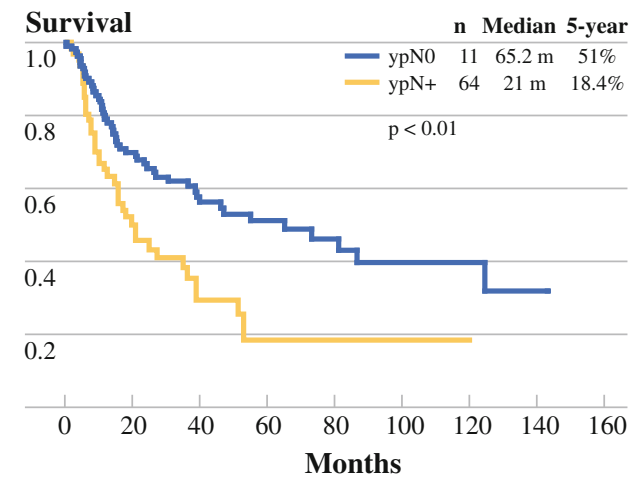

d

Survival n Median 5-year \begin{tabular}{lllll}
\hline 1.0 & $-\mathrm{ypV} 0$ & 23 & $21.1 \mathrm{~m}$ & $27.4 \%$ \\
$-\mathrm{ypV}+$ & 41 & $17.4 \mathrm{~m}$ & $12.5 \%$
\end{tabular}
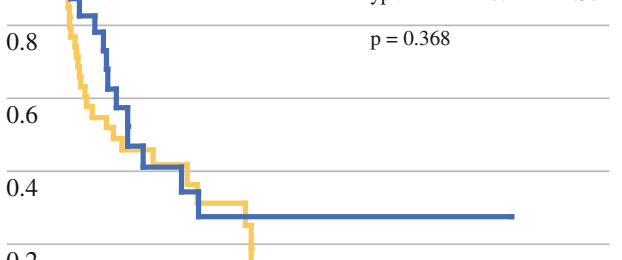
0.2

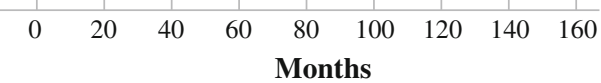

TABLE 2 Multivariate analysis on factors predictive of survival of patients treated with neoadjuvant chemoradiation and surgery

\begin{tabular}{lllr}
\hline & HR & $95 \%$ CI & $P$ value \\
\hline $\begin{array}{l}\text { Gender } \\
\text { Male }\end{array}$ & 3.011 & $1.381-6.567$ & .006 \\
$\quad \begin{array}{l}\text { Female (reference) } \\
\text { ypN stage }\end{array}$ & 1 & & \\
$\quad$ ypN0 (reference) & 1 & & \\
$\quad$ ypN1 & 1.713 & $1.118-2.625$ & .013 \\
ypV stage & 1.362 & $1.151-1.612$ & $<.001$ \\
\hline
\end{tabular}

$H R$ hazard ratio, $C I$ confidence interval

Reference against which hazard rations are calculated gical resection alone without prior treatment there was a linear relationship between the chance of nodal metastasis and pT stage, this clear association was lost in those who had had chemoradiation. ${ }^{7}$ Response in the primary tumor does not necessarily imply equal response in the lymph nodes. The metastatic cells may behave differently, or they may be located outside the irradiation field.

There are difficulties assigning ypT stage in patients who had prior treatment. The conventional TNM classification denotes a pT stage according to the deepest layer of the esophageal wall that is infiltrated by the tumor. After neoadjuvant treatment, this simple gradation is lost. Often only small clusters of residual viable cells are found in the deep layer of the esophagus, with the superficial layers 
TABLE 3 Multivariate analysis on factors predictive of survival with residual viable cell as categorical variable

\begin{tabular}{lllr}
\hline & HR & $95 \%$ CI & $P$ value \\
\hline $\begin{array}{l}\text { Gender } \\
\text { Male }\end{array}$ & 3.042 & $1.390-6.567$ & .005 \\
$\quad \begin{array}{l}\text { Female (reference) } \\
\text { ypN stage }\end{array}$ & 1 & & \\
$\quad$ ypN0 (reference) & 1 & & \\
ypN1 & 1.712 & $1.117-2.624$ & .014 \\
ypV stage & & & .005 \\
ypV0 (reference) & 1 & & \\
ypV1 & 1.561 & $0.912-2.672$ & .105 \\
ypV2 & 1.829 & $0.894-3.739$ & .098 \\
ypV3 & 2.592 & $1.530-4.386$ & $<.001$ \\
\hline
\end{tabular}

$H R$ hazard ratio, $C I$ confidence interval

Reference against which hazard rations are calculated

V0: No residual viable malignant cell in primary tumor. V1: $1 \%-33 \%$ of residual malignant cell remaining in primary tumor. V2: $34 \%-66 \%$ of residual malignant cell remaining in primary tumor. V3: $67 \%-$ $100 \%$ of residual malignant cell remaining in primary tumor

sterilized. It is not clear if assigning a ypT stage according to this layer is appropriate. Instead, looking at the percent of residual viable tumor may be a better way to measure the severity of disease status.

Different grading systems have been reported to assess the degree of primary tumor response after neoadjuvant therapy (Table 4). Mandard and associates first reported the importance of taking into account the degree of tumor regression as an important survival prognostic factor. ${ }^{28}$ The grading system was based on the amount of residual viable cells and posttherapeutic fibrosis. Schneider divided the percent of viable cells into $0 \%,<10 \%, 10 \%-50 \%$, and $>50 \%{ }^{11}$ Chirieac used slightly different dividing points as $0 \%, 1 \%-50 \%$, and $>50 \%{ }^{8}$ The Japanese Society for Esophageal Disease published a guideline to assess the degree of primary tumor response by dividing the proportions of viable cell into thirds. ${ }^{16}$ From our data, it seems certain that $\mathrm{ypV}$ is of prognostic significance both as a continuous or a categorical variable (Tables 2 and 3). For the ease of daily clinical application, the ability to divide $\mathrm{ypV}$ into discrete grades could be useful. A clear trend is seen in survival from ypV0 to ypV3 (Fig. 2e). However, the choice of different categories is arbitrary. Consistently reproducible categories are not yet available in the literature. This may in part be related to different ways of assessing histological regression. One potential limitation on assessing the percent of viable cells is that spontaneous tumor necrosis can occur in any tumor, particularly if the necrosis is confined to the center of a large tumor cell clump, and this may not be related to treatment effect. Distinction between the two mechanisms is not possible by histological examination. A scar area is presumed to have developed after tumor necrosis. However, scarring might occur without prior tumor's presence.

Undoubtedly, nodal status is an important prognostic factor. The ypN stage is shown in the present study as an important factor. Gaca et al. demonstrated in 101 patients who had chemoradiation that the ypN status was the only
TABLE 4 Currently available grading systems for evaluation of the primary tumor response after chemoradiation therapy

\begin{tabular}{lll}
\hline Authors & $\begin{array}{l}\text { Tumor } \\
\text { grading }\end{array}$ & Features of primary tumor \\
\hline Chirieac LR et al. $2005^{8}$ & 1 & $0 \%$ of residual cell \\
& 2 & $1 \%-50 \%$ of residual viable cell \\
& 3 & $>50 \%$ of residual viable cell in primary tumor \\
Schneider PM et al. ${ }^{11}$ & 1 & $10 \%-50 \%$ VTRCs \\
& 2 & $<10 \%$ VTRCs \\
Japanese Society & 3 & 0 VTRCs \\
of Esophageal Disease ${ }^{16}$ & 4 & Ineffective \\
& 1 & Slightly effective: Viable cell more than $1 / 3$ of tumor \\
tissue, but with evidence of degeneration
\end{tabular}


prognostic factor for disease-free survival. ${ }^{29}$ Similar findings were reported by Reynolds et al. ${ }^{27}$ It is important to note that in our patients who had ypN0 disease, ypV0 patients survived longer than those who had $\mathrm{ypV}+$ disease. This difference was not significant in patients who had nodal metastases $(\mathrm{ypN}+)$. This is not unexpected as the importance of metastatic disease overrides the status of the primary tumor.

In summary, we have shown that the pretherapeutic clinical TNM stage has no prognostic value in patients who had neoadjuvant chemoradiation. Gender, nodal status, and the percent of residual viable cells in the primary tumor were independent prognostic factors. $\mathrm{ypV}$ assessment should replace conventional ypT stage as a prognostic factor.

OPEN ACCESS This article is distributed under the terms of the Creative Commons Attribution Noncommercial License which permits any noncommercial use, distribution, and reproduction in any medium, provided the original author(s) and source are credited.

\section{REFERENCES}

1. Greene FL, Page DL, Fleming ID, Fritz A, Balch CM, Haller DG, Morrow M, editors. American Joint Committee on Cancer: AJCC cancer staging manual. 6th ed. New York: Springer; 2002.

2. Steup WH, De Leyn P, Deneffe G, Van Raemdonck D, Coosemans W, Lerut T. Tumors of the esophagogastric junction. Long-term survival in relation to the pattern of lymph node metastasis and a critical analysis of the accuracy or inaccuracy of pTNM classification. J Thorac Cardiovasc Surg. 1996;111:85-94; discussion 5.

3. Urba SG, Orringer MB, Turrisi A, Iannettoni M, Forastiere A, Strawderman M. Randomized trial of preoperative chemoradiation versus surgery alone in patients with locoregional esophageal carcinoma. J Clin Oncol. 2001;19:305-13.

4. Walsh TN, Noonan N, Hollywood D, Kelly A, Keeling N, Hennessy TP. A comparison of multimodal therapy and surgery for esophageal adenocarcinoma. New Engl J Med. 1996;335:462-7.

5. Coia LR, Minsky BD, Berkey BA, John MJ, Haller D, Landry J, et al. Outcome of patients receiving radiation for cancer of the esophagus: results of the 1992-1994 Patterns of Care Study. $J$ Clin Oncol. 2000;18:455-62.

6. Suntharalingam M, Moughan J, Coia LR, Krasna MJ, Kachnic L, Haller DG, et al. The national practice for patients receiving radiation therapy for carcinoma of the esophagus: results of the 1996-1999 Patterns of Care Study. Int J Radiat Oncol Biol Phys. 2003;56:981-7.

7. Law S, Kwong DL, Wong KH, Kwok KF, Wong J. The effects of neoadjuvant chemoradiation on pTNM staging and its prognostic significance in esophageal cancer. J Gastrointest Surg. 2006;10: 1301-11.

8. Chirieac LR, Swisher SG, Ajani JA, Komaki RR, Correa AM, Morris JS, et al. Posttherapy pathologic stage predicts survival in patients with esophageal carcinoma receiving preoperative chemoradiation. Cancer. 2005;103:1347-55.

9. Rizk NP, Venkatraman E, Bains MS, Park B, Flores R, Tang L, et al. American Joint Committee on Cancer staging system does not accurately predict survival in patients receiving multimodality therapy for esophageal adenocarcinoma. J Clin Oncol. 2007; 25:507-12.
10. Swisher SG, Hofstetter W, Wu TT, Correa AM, Ajani JA, Komaki RR, et al. Proposed revision of the esophageal cancer staging system to accommodate pathologic response (pP) following preoperative chemoradiation (CRT). Ann Surg. 2005;241: 810-7; discussion 817-20.

11. Schneider PM, Baldus SE, Metzger R, Kocher M, Bongartz R, Bollschweiler E, et al. Histomorphologic tumor regression and lymph node metastases determine prognosis following neoadjuvant radiochemotherapy for esophageal cancer: implications for response classification. Ann Surg. 2005;242:684-92.

12. Brucher BL, Becker K, Lordick F, Fink U, Sarbia M, Stein H, et al. The clinical impact of histopathologic response assessment by residual tumor cell quantification in esophageal squamous cell carcinomas. Cancer. 2006;106:2119-27.

13. Lam KY, Law S, Ma LT, Ong SK, Wong J. Pre-operative chemotherapy for squamous cell carcinoma of the oesophagus: do histological assessment and p53 overexpression predict chemoresponsiveness? Eur J Cancer. 1997;33:1221-5.

14. Law S, Wong J. Two-field dissection is enough for esophageal cancer. Dis Esophagus. 2001;14:98-103.

15. Tabira Y, Okuma T, Sakaguchi T, Kuhara H, Teshima K, Kawasuji M. Three-field dissection or two-field dissection?-A proposal of new algorithm for lymphadenectomy. Hepatogastroenterology. 2004;51:1015-20.

16. Japanese DEfS. Guidelines for clinical and pathologic studies on carcinoma of the esophagus, ninth edition. Esophagus. 2004:61$88,107-25$.

17. Medical Research Council Oesophageal Cancer Working Group. Surgical resection with or without preoperative chemotherapy in oesophageal cancer: a randomised controlled trial. Lancet. 2002;359:1727-33.

18. Kelsen DP, Ginsberg R, Pajak TF, Sheahan DG, Gunderson L, Mortimer J, et al. Chemotherapy followed by surgery compared with surgery alone for localized esophageal cancer. $N$ Engl J Med. 1998;339:1979-84.

19. Bosset JF, Gignoux M, Triboulet JP, Tiret E, Mantion G, Elias D, et al. Chemoradiotherapy followed by surgery compared with surgery alone in squamous-cell cancer of the esophagus. New Engl J Med. 1997;337:161-7.

20. Le Prise E, Etienne PL, Meunier B, Maddern G, Ben Hassel M, Gedouin $\mathrm{D}$, et al. A randomized study of chemotherapy, radiation therapy, and surgery versus surgery for localized squamous cell carcinoma of the esophagus. Cancer. 1994;73:1779-84.

21. Nygaard K, Hagen S, Hansen HS, Hatlevoll R, Hultborn R, Jakobsen A, et al. Pre-operative radiotherapy prolongs survival in operable esophageal carcinoma: a randomized, multicenter study of pre-operative radiotherapy and chemotherapy. The second Scandinavian trial in esophageal cancer. World J Surg. 1992;16: 1104-9; discussion 1110.

22. Forastiere AA, Orringer MB, Perez-Tamayo C, Urba SG, Zahurak M. Preoperative chemoradiation followed by transhiatal esophagectomy for carcinoma of the esophagus: final report. $J$ Clin Oncol. 1993;11:1118-23.

23. Ancona E, Ruol A, Santi S, Merigliano S, Sileni VC, Koussis H, et al. Only pathologic complete response to neoadjuvant chemotherapy improves significantly the long term survival of patients with resectable esophageal squamous cell carcinoma: final report of a randomized, controlled trial of preoperative chemotherapy versus surgery alone. Cancer. 2001;91:2165-74.

24. Swisher SG, Ajani JA, Komaki R, Nesbitt JC, Correa AM, Cox $\mathrm{JD}$, et al. Long-term outcome of phase II trial evaluating chemotherapy, chemoradiotherapy, and surgery for locoregionally advanced esophageal cancer. Int J Radiat Oncol Biol Phys. 2003; $57: 120-7$. 
25. Geh JI, Crellin AM, Glynne-Jones R. Preoperative (neoadjuvant) chemoradiotherapy in oesophageal cancer. Br J Surg. 2001;88: 338-56.

26. Enzinger PC, Mayer RJ. Esophageal cancer. $N$ Engl J Med. 2003;349:2241-52.

27. Reynolds JV, Muldoon C, Hollywood D, Ravi N, Rowley S, O'Byrne K, et al. Long-term outcomes following neoadjuvant chemoradiotherapy for esophageal cancer. Ann Surg. 2007;245: 707-16.
28. Mandard AM, Dalibard F, Mandard JC, Marnay J, Henry-Amar $\mathrm{M}$, Petiot JF, et al. Pathologic assessment of tumor regression after preoperative chemoradiotherapy of esophageal carcinoma. Clinicopathologic correlations. Cancer. 1994;73:2680-6.

29. Gaca JG, Petersen RP, Peterson BL, Harpole DH Jr, D'Amico TA, Pappas TN, et al. Pathologic nodal status predicts diseasefree survival after neoadjuvant chemoradiation for gastroesophageal junction carcinoma. Ann Surg Oncol. 2006;13:340-6. 